\title{
VIDEO-ANALYSIS OF CONFLICT SITUATIONS ON SELECTED ROUNDABOUTS IN THE CZECH REPUBLIC
}

The paper deals with video-analysis of conflict situations in road traffic and presents results of researches which were performed on selected roundabouts in the Czech Republic. This article refers to suitability of usage video-recording to analysis of behavior of participants of road traffic and also to monitoring of the danger places on the roundabouts. There are results of analyses which were performed in 2010 and also comparative analysis of conflict situations and possible traffic accidents.

Keywords: Conflict Situation, Roundabout, Road Transport

\section{Introduction}

Road safety is the current focus of public debate. Dangerous places on the road are still a lot and any modification to increase safety is welcomed. Traffic designer can never deem his traffic solution as absolutely safe. And just the video-analysis of conflict situations can help designer, for example, to design reconstruction of some intersection with a lot of traffic accidents. Some dangerous hidden factors (which occur on the intersections) can be detected early and the designer can avoid his possible mistakes.

The usage of video-recording is very substantial and advantageous. It can be analyzed collectively and repeatedly. Disturbing influences of the road traffic (e.g. noise, dust etc.) and weather (e.g. temperature, wind, rain, etc.) are eliminated.

And what does the term "Conflict situation" mean? Conflict situation is a moment or a situation in road traffic when participants of road traffic are or can be endangered by other participants. The conflict situation predates every traffic accident. Every conflict situation is described by the symbol which includes description of participants of conflict situation, source of conflict situation and seriousness of conflict situation [1] - [3].

\section{Selection of roundabouts for analysis of conflict situations}

The video-recordings of traffic were made within the project [4] on selected roundabouts in the Czech Republic:

- Dukelska - Jeremenkova - Premyslovcu, Novy Jicin (NJ1),

- Premyslovcu - Sokolovska - Palackeho, Novy Jicin (NJ2),

- Sokolovska - Msgr. Sramka - Stefanikova, Novy Jicin (NJ3),
- Sokolovska - Bezrucova - Zborovska - gen. Hlado, Novy Jicin (NJ4),

- Zborovska - Machova - Karla Kryla, Novy Jicin (NJ5),

- Masarykova - parking Tesco, Valasske Mezirici (VM1),

- Masarykova - Hulince - Hrbitovni, Valasske Mezirici (VM3),

- Masarykova - Roznovska - Nadrazni, Valasske Mezirici (VM4),

- Masarykova - Zasovska - Vsetínska - Krizna, Valasske Mezirici (VM5),

- Vsetinska - Zerotinova - Sokolska, Valasske Mezirici (VM6),

- Ostravska - Zeleznicaru - U Nadrazi - Orlovska - Hl. trida U Motelu, Havirov (HAV1),

- Zeleznicaru - U Nadrazi, Havirov (HAV2),

- Beskydska - parking Tesco, Frydek-Mistek (FM),

- Sokolska - 30. dubna, Ostrava (OV),

- Havlickova - Polepska - Jaselska - U Krizovatky - Dukelskych hrdinu, Kolin (KOL),

- Rysaveho - Pod Chodovem - Roztylska - U Kunratickeho lesa, Prague (PHA).

The roundabouts HAV1, FM and PHA are double-lane roundabouts and the others are single-lane roundabouts. The roundabouts NJ1 and VM1 have three legs, the roundabout KOL has five legs, the roundabout HAV1 has six legs and the others have four legs.

\section{Video-Analysis of Conflict Situations}

The volumes of traffic flows and their directions were detected from each recording. Video-analyses of conflict situations were performed using a methodology of the Folprecht's video-analysis of conflict situations [1].

\footnotetext{
* Vladislav Krivda

Department of Transport Constructions, Faculty of Civil Engineering, VSB - Technical University of Ostrava, Ostrava-Poruba, Czech Republic, Email: vladislav.krivda@vsb.cz
} 
Every conflict situation is described by the symbol which includes three parts:

- one number - description of participants of conflict situation, e.g. $1=$ pedestrian, $2=$ car, $4=$ pedestrian and car, $6=$ two or more cars, $9=$ other (one cyclist, cyclist and car etc.) [1],

- one or more letters - description of source of conflict situation, e.g. $n=$ violation of rule "yield to...,$f_{p}=$ influence of pedestrian crossing, $f_{k}=$ influence of near intersection, $j_{c}=$ wrong ride of cyclist, $a=$ aggression, $g=$ giving priority against rule, $o=$ restriction or danger in driving during change of the lane or during exiting the roundabout, $D=$ danger of rear-end collision, $j_{o}=$ wrong way of drive (very near curb) etc. [2], [3] (more see Chapter 4 or Tab. 4),

- one number $(1-4)$ - description of seriousness of conflict situation. [1]:

The seriousness of conflict situation is described as follows

- the $1^{\text {st }}$ level - potential conflict situations,

- the $2^{\text {nd }}$ level - conflict situations when one or more participants are restricted,

- the $3^{\text {rd }}$ level - conflict situations when one or more participants are endangered,

- the $4^{\text {th }}$ level - traffic accident.

For example the symbol $6 a 3$ means aggression $(a)$ between two drivers of cars $(6)$ and $3^{\text {rd }}$ level of seriousness (3) - details see below or [1] - [3].

The resulting number of conflict situations was recalculated to coefficient of relative conflictness $c_{R}$ :

$$
c_{R}=\frac{N_{C S}}{V} \cdot 100[C S / 100 \mathrm{veh}]
$$

where:

$N_{C S}$ - number of conflict situations (CS) per hour [CS/h]

$V$ - hour traffic volume $[\mathrm{veh} / \mathrm{h}]$
The coefficient $c_{R}$ is usually determined only for the conflict situations between two (or more) participants of road traffic.

We also distinguish several kinds of conflict situations (details see [1] - [3]):

- "own" conflict situation - a conflict situation which is related to traffic on the roundabout, its construction etc.,

- "non-own" conflict situation - a conflict situation which is influenced by other conflict situation in the vicinity (for example, on other intersection),

- "primary" conflict situation - a conflict situation which isn't caused by other conflict situation,

- "secondary" conflict situation - a conflict situation which is caused by other conflict situation.

Some video-recordings of conflict situations (WMV format) are on this web page: https://sites.google.com/site/krivda0ks/videoanalyzy (in Czech). The list of selected conflict situations is in Tab. 1 - 3 .

\section{Conflict Situations (CS) versus Traffic Accidents (TA)}

Some important conflict situations are described below, including considerations about the type of traffic accident, which can be caused by conflict situation. We distinguish several kinds of traffic accidents [4], [5]:

- crash with moving vehicle (head-on, side or rear-end collision),

- crash with parked vehicle,

- crash with obstacle (tree, traffic sign, crash barrier, curb, wall etc.),

- crash with pedestrian, tram etc.

The most important conflict situations (identified from videoanalysis on the roundabouts):

- Violation of rule "yield to ..." (conflict situation $6 n 2$ or $6 n 3$ ) - the conflict situation, when a vehicle entering the roundabout doesn't

The list of selected conflict situations on roundabouts in Novy Jicin ( $N_{C S}[\mathrm{CS} / \mathrm{h}], V$ [veh/h], $\left.c_{R}[\mathrm{CS} / 100 \mathrm{veh}]\right)$

Tab. 1

\begin{tabular}{|c|c|c|c|c|c|c|c|c|c|c|}
\hline \multirow{2}{*}{$\begin{array}{l}\text { Conflict } \\
\text { situation* }\end{array}$} & \multicolumn{2}{|c|}{ NJ1 } & \multicolumn{2}{|c|}{ NJ2 } & \multicolumn{2}{|c|}{$\mathrm{NJ3}$} & \multicolumn{2}{|c|}{ NJ4 } & \multicolumn{2}{|c|}{ NJ5 } \\
\hline & $N_{C S}$ & $c_{R}$ & $N_{C S}$ & $c_{R}$ & $N_{C S}$ & $c_{R}$ & $N_{C S}$ & $c_{R}$ & $N_{C S}$ & $c_{R}$ \\
\hline 9jc1 & 3 & 0.19 & 5 & 0.33 & 10 & 0.61 & 1 & 0.05 & 6 & 0.55 \\
\hline $6 f_{k} 2$ & 6 & 0.40 & & & & & & & & \\
\hline $6 \mathrm{n} 2,6 \mathrm{n} 3 \ldots$ & 5 & 0.32 & & & 3 & 0.18 & 8 & 0.42 & 6 & 0.55 \\
\hline $4 f_{p} 2$ & 4 & 0.26 & 21 & 1.39 & 16 & 0.98 & 42 & 2,18 & 14 & 1.28 \\
\hline $6 \mathrm{~g} 2$ & 2 & 0.13 & 1 & 0.07 & & & 2 & 0.10 & 1 & 0.09 \\
\hline 6D3 & 1 & 0.06 & 3 & 0.20 & 1 & 0.06 & 4 & 0.21 & 3 & 0.27 \\
\hline 9jc2 & & & & & 4 & 0.25 & & & 1 & 0.09 \\
\hline 6a2,6a3... & & & & & & & 5 & 0.26 & & \\
\hline$V$ & \multicolumn{2}{|c|}{1547} & \multicolumn{2}{|c|}{1506} & \multicolumn{2}{|c|}{1630} & \multicolumn{2}{|c|}{1926} & \multicolumn{2}{|c|}{1094} \\
\hline$c_{R}$ & \multicolumn{2}{|c|}{0.96} & \multicolumn{2}{|c|}{2.13} & \multicolumn{2}{|c|}{1.59} & \multicolumn{2}{|c|}{3.47} & \multicolumn{2}{|c|}{2.91} \\
\hline
\end{tabular}

*) see above (or Chapter 4 and Tab. 4) 
The list of selected conflict situations on roundabouts in Valasske Mezirici $\left(N_{C S}[\mathrm{CS} / \mathrm{h}], V[\mathrm{veh} / \mathrm{h}], c_{R}[\mathrm{CS} / 100 \mathrm{veh}]\right)$

Tab. 2

\begin{tabular}{|c|c|c|c|c|c|c|c|c|c|c|}
\hline \multirow{2}{*}{$\begin{array}{l}\text { Conflict } \\
\text { situation* }\end{array}$} & \multicolumn{2}{|c|}{ VM1 } & \multicolumn{2}{|c|}{ VM3 } & \multicolumn{2}{|c|}{ VM4 } & \multicolumn{2}{|c|}{ VM5 } & \multicolumn{2}{|c|}{ VM6 } \\
\hline & $N_{C S}$ & $c_{R}$ & $N_{C S}$ & $c_{R}$ & $N_{C S}$ & $c_{R}$ & $N_{C S}$ & $c_{R}$ & $N_{C S}$ & $c_{R}$ \\
\hline 9jc1 & & & 3 & 0.18 & 1 & 0.05 & 12 & 0.62 & 3 & 0.14 \\
\hline $2 \mathrm{jo} 1$ & 23 & 1.78 & & & & & & & & \\
\hline $6 f_{k} 2$ & 5 & 0.39 & & & & & & & & \\
\hline $6 \mathrm{n} 2 \ldots$ & & & 6 & 0.36 & 14 & 0.65 & 13 & 0.67 & 8 & 0.37 \\
\hline $6 n 3 \ldots$ & & & 4 & 0.24 & 3 & 0.14 & 3 & 0.15 & 4 & 0.19 \\
\hline $4 f_{p} 2$ & 1 & 0.08 & & & 5 & 0.23 & 12 & 0.62 & 45 & 2.13 \\
\hline $6 \mathrm{~g} 2$ & & & 2 & 0.12 & 2 & 0.09 & 7 & 0.36 & 5 & 0.24 \\
\hline 6D3 & & & & & & & 2 & 0.10 & & \\
\hline 9jc2, 9jc3 & & & & & 1 & 0.05 & 3 & 0.15 & 2 & 0.09 \\
\hline$V$ & \multicolumn{2}{|c|}{1290} & \multicolumn{2}{|c|}{1648} & \multicolumn{2}{|c|}{2141} & \multicolumn{2}{|c|}{1942} & \multicolumn{2}{|c|}{2115} \\
\hline$c_{R}$ & \multicolumn{2}{|c|}{2.41} & \multicolumn{2}{|c|}{0.90} & \multicolumn{2}{|c|}{1.16} & \multicolumn{2}{|c|}{2.30} & \multicolumn{2}{|c|}{3.13} \\
\hline
\end{tabular}

*) see above (or Chapter 4 and Tab. 4)

The list of selected conflict situations on the other roundabouts $\left(N_{C S}[\mathrm{CS} / \mathrm{h}], V\right.$ [veh/h], $\left.c_{R}[\mathrm{CS} / 100 \mathrm{veh}]\right)$

Tab. 3

\begin{tabular}{|c|c|c|c|c|c|c|c|c|c|c|c|c|}
\hline \multirow{2}{*}{$\begin{array}{c}\text { Conflict } \\
\text { situation* }\end{array}$} & \multicolumn{2}{|c|}{ HAV1 } & \multicolumn{2}{|c|}{ HAV2 } & \multicolumn{2}{|c|}{ FM } & \multicolumn{2}{|c|}{$\mathrm{OV}$} & \multicolumn{2}{|c|}{ KOL } & \multicolumn{2}{|c|}{ PHA } \\
\hline & $N_{C S}$ & $c_{R}$ & $N_{C S}$ & $c_{R}$ & $N_{C S}$ & $c_{R}$ & $N_{C S}$ & $c_{R}$ & $N_{C S}$ & $c_{R}$ & $N_{C S}$ & $c_{R}$ \\
\hline 9jc1 & & & & & & & 1 & 0.06 & 5 & 0.18 & & \\
\hline 6fk2 & & & 14 & 0.85 & & & 10 & 0.63 & & & & \\
\hline $6 n 2,6 n 3 \ldots$ & 10 & 0.27 & 4 & 0.24 & 12 & 0.43 & 1 & 0.06 & 28 & 1.03 & 6 & 0.21 \\
\hline $4 \mathrm{fp} 2$ & 1 & 0.03 & 4 & 0.24 & & & 26 & 1.64 & 23 & 0.84 & & \\
\hline $6 \mathrm{~g} 2$ & 19 & 0.51 & 11 & 0.67 & & & 3 & 0.19 & 10 & 0.37 & & \\
\hline 6D3 & & & & & 1 & 0.04 & & & 4 & 0.15 & & \\
\hline 9jc2 & & & 1 & 0.06 & & & 1 & 0.06 & & & & \\
\hline 6a2,6a3... & 17 & 0.45 & & & & & 5 & 0.31 & 4 & 0.15 & 1 & 0.03 \\
\hline $602,603 \ldots$ & 11 & 0.30 & & & 16 & 0.58 & & & & & 2 & 0.07 \\
\hline 6D4 & 1 & 0.03 & & & & & & & & & & \\
\hline V & \multicolumn{2}{|c|}{3747} & \multicolumn{2}{|c|}{1648} & \multicolumn{2}{|c|}{2762} & \multicolumn{2}{|c|}{1590} & \multicolumn{2}{|c|}{2722} & \multicolumn{2}{|c|}{2884} \\
\hline$c_{R}$ & \multicolumn{2}{|c|}{1.89} & \multicolumn{2}{|c|}{2.18} & \multicolumn{2}{|c|}{1.05} & \multicolumn{2}{|c|}{4.97} & \multicolumn{2}{|c|}{3.19} & \multicolumn{2}{|c|}{0.55} \\
\hline
\end{tabular}

*) see above (or Chapter 4 and Tab. 4)

yield to a vehicle on circulating roadway. The situations $6 \mathrm{n} 2$ (or $6 \mathrm{n} 3$ ) occurred on all monitored roundabouts, especially on roundabouts VM4, VM5, HAV1, FM and KOL. This conflict situation can cause traffic accident of type "crash with moving vehicle (side collision)" (cause: against "YIELD TO").

- Stopping or decelerating of traffic on circulating roadway due to queue of vehicles before pedestrian crossing (conflict situation $\left.4 f_{p} 2\right)$ - the pedestrian crossing near roundabout can cause a queue of vehicles which extends to circulating roadway. The traffic on roundabout is stopped or decelerated. Some vehicles go round the stopped vehicles using the truck apron (the truck apron or the curb of the central island can be damaged - see Fig. 1). This situation occurred on roundabouts VM4 and VM5 and especially on roundabout VM6. This conflict situation can cause traffic accident of type "crash with moving vehicle (rearend collision)".
- Stopping or decelerating of traffic on circulating roadway due to queue of vehicles on other near intersection (conflict situation $4 f_{k} 2$ ) - the other intersection (which is relatively near roundabout; usually other roundabout or intersection with traffic lights) can also cause a queue of vehicles which extends to circulating roadway. The traffic on roundabout is stopped or decelerated. This situation occurred on roundabouts NJ1, VM1 and HAV2 (near intersection is also roundabout) and on roundabout $\mathrm{OV}$ (near intersection is intersection with traffic lights). This conflict situation can also cause traffic accident of type "crash with moving vehicle (rear-end collision)".

- Wrong ride of cyclist on circulating roadway (conflict situation 9jc1 or 9jc2) - the conflict situation, when a cyclist doesn't ride on the right side of the circulating roadway (but on center or the left side of the circulating roadway or even on the truck apron). The situations 9jc1 or 9jc2 occurred on roundabouts VM5 and 

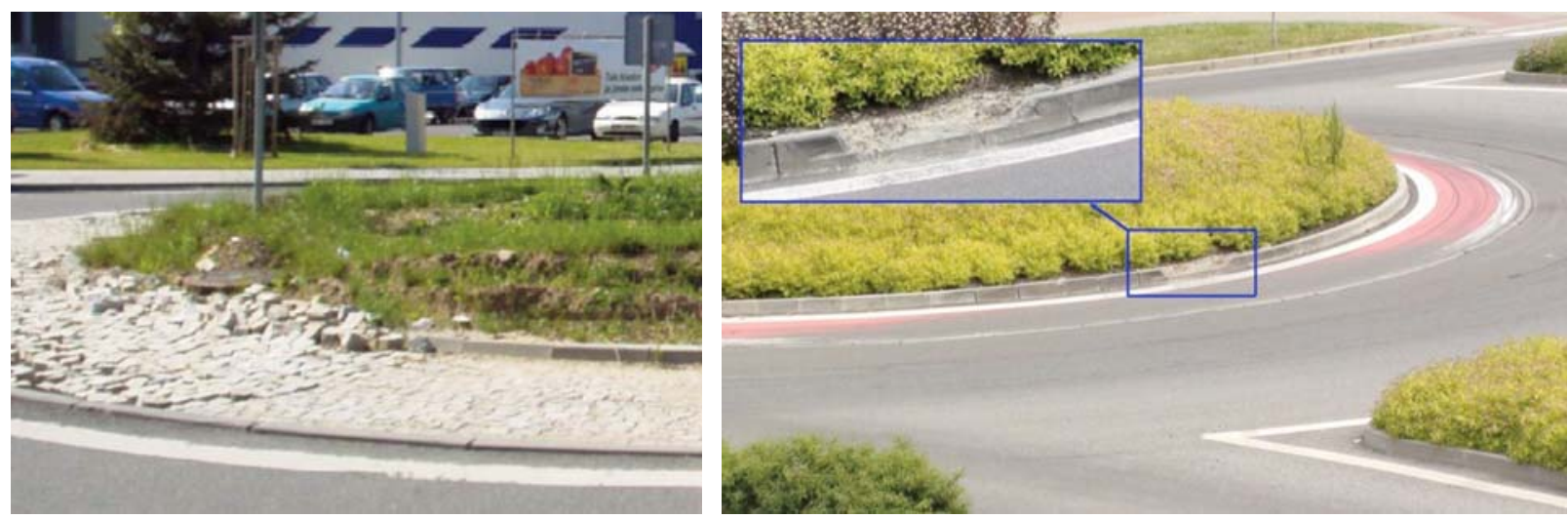

Fig. 1 Damaged truck apron and curb of the central island

NJ3. This conflict situation can cause traffic accident of type "crash with moving vehicle (rear-end collision)" or "crash with moving vehicle (side collision)".

- Giving priority against rule (conflict situation 6g2) - the conflict situation, when a vehicle on circulating roadway yields to a vehicle entering the roundabout (against rule). The driver of vehicle on circulating roadway stops or decelerates and yields to vehicle on entry. The driver entering the roundabout needn't understand it, he starts to behave chaotically (slowly to drive on, to stop etc.). The vehicles can suddenly pull away together and crash. This situation occurred on all monitored roundabouts, especially on roundabouts HAV1, HAV2 and KOL. This conflict situation can cause traffic accident of type "crash with moving vehicle (side collision)" (cause: against "YIELD TO”). However, this conflict situation can also cause traffic accident of type "crash with moving vehicle (rear-end collision)" in a queue of vehicles entering the roundabout.

- Aggression (conflict situation $6 a 2$ or $6 a 3$ ) - there is a lot of aggressive behavior on the roundabout, for example overtaking a queue of vehicles entering the roundabout. This situation occurred on roundabout with wide single-lane entries and especially on roundabout HAV1. This conflict situation can cause traffic accident of type "crash with moving vehicle (side collision)".

- Wrong way of drive - very close to the curb (conflict situation $\left.2 j_{o} l\right)$ - the conflict situation, when a vehicle (usually truck) exiting the roundabout goes very close to the right curb (the curb can be damaged - see Fig. 2). This conflict situation can cause traffic accident of type "crash with obstacle (curb)".

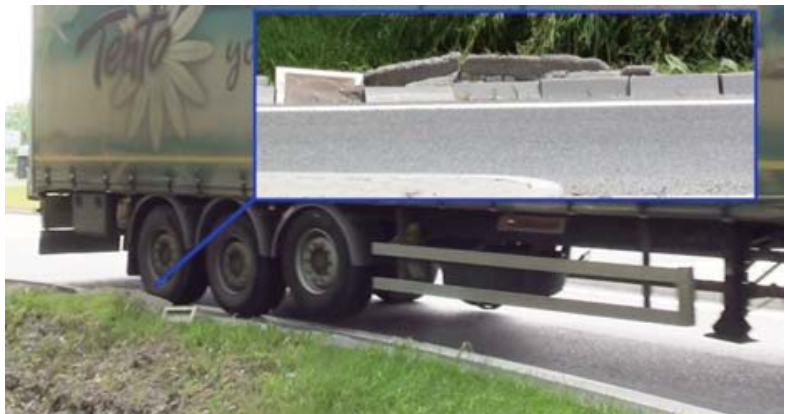

Fig. 2 Damaged right curb (roundabout VM1)

- Restriction or danger in driving during change of the lane or during exiting the roundabout (conflict situations 6o2, 603 etc. - see Figs. 3 and 4). These conflict situations usually occur on double-lane roundabouts and can cause traffic accident of type "crash with moving vehicle (side collision)" (cause: "change of the lane”).

Exiting the roundabout is very problematical especially on multi-lane roundabouts. Two accidents happened on monitored roundabouts. The first one happened on roundabout FM immediately before our measuring. The driver of the vehicle in the left lane wanted to exit roundabout, but the driver of the vehicle in the right lane wanted to move on the circulating roadway. This conflict situation (or more exactly the accident) is classified as 604 (see Figs. 4 or 5).
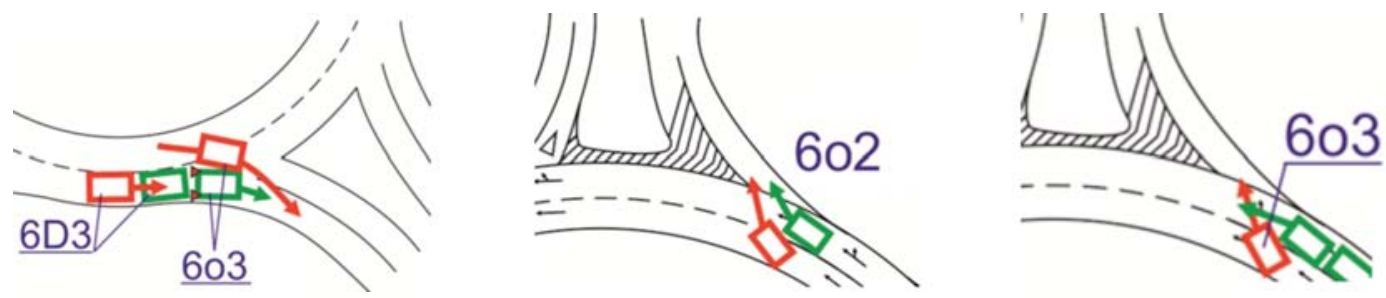

Fig. 3 Some conflict situations of type 6o2, 603 (red car restricted or endangered green car) 


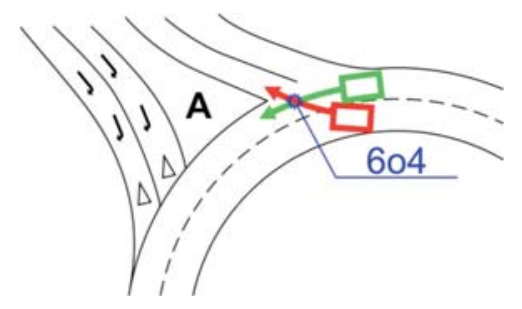

Fig. 4 Scheme of traffic accident 604

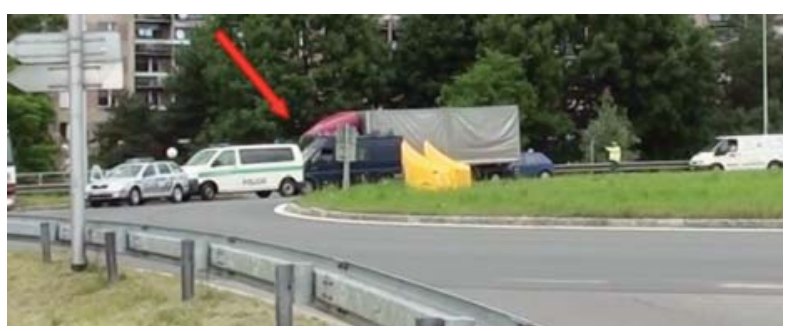

Fig. 5 Traffic accident 604

The second accident happened on roundabout HAV1 during our measuring (see Figs. 6 or 7). The vehicle Veh1 on the circulating roadway crashed into the vehicle Veh2 rear-end (conflict situation $6 D 4$ - see Fig. 6). This accident was caused by previous "primary" conflict situation (6o3 - see Fig. 6), when other vehicle had dangerously left the roundabout.

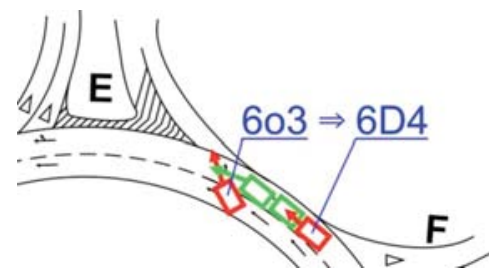

Fig. 6 Scheme of traffic accident 6D4

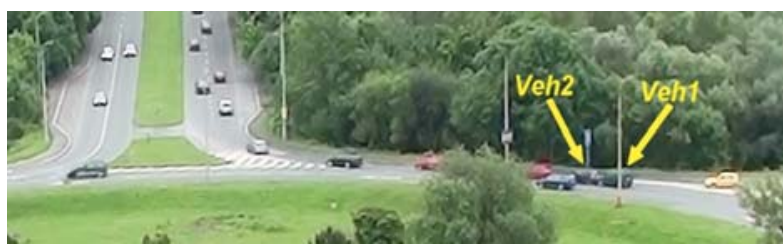

Fig. 7 Traffic accident $6 D 4$

\section{Conclusions}

The most important monitored conflict situations are in Tab. 4. There are also types of traffic accidents which can be caused by the conflict situations.
The list of selected conflict situations

Tab. 4 and traffic accidents

\begin{tabular}{|c|c|}
\hline Conflict situation ==> & $==>$ Traffic accident \\
\hline $\begin{array}{l}\text { 6n2, } 6 \mathrm{n} 3 \text { - Violation of rule "yield } \\
\text { to ..." }\end{array}$ & $\begin{array}{l}\text { "Crash with moving vehicle (side } \\
\text { collision)" (cause: against } \\
\text { "YIELD TO") }\end{array}$ \\
\hline $\begin{array}{l}\mathbf{4 f}_{\mathrm{p}} \mathbf{2} \text { - Stopping or decelerating of } \\
\text { traffic on circulating roadway due } \\
\text { to queue of vehicles before pedes- } \\
\text { trian crossing }\end{array}$ & $\begin{array}{l}\text { "Crash with moving vehicle (rear- } \\
\text { end collision)" }\end{array}$ \\
\hline $\begin{array}{l}\mathbf{6} \mathbf{f}_{\mathbf{k}} \mathbf{2} \text { - Stopping or decelerating of } \\
\text { traffic on circulating roadway due } \\
\text { to queue of vehicles on other near } \\
\text { intersection ("non-own" conflict } \\
\text { situation) }\end{array}$ & $\begin{array}{l}\text { "Crash with moving vehicle (rear- } \\
\text { end collision)" }\end{array}$ \\
\hline $\begin{array}{l}\text { 9jc1, 9jc2 - Wrong ride of cyclist } \\
\text { on circulating roadway }\end{array}$ & $\begin{array}{l}\text { "Crash with moving vehicle (rear- } \\
\text { end collision)" or "Crash with } \\
\text { moving vehicle (side collision)" }\end{array}$ \\
\hline 6a2, 6a3 - Aggression & $\begin{array}{l}\text { "Crash with moving vehicle (side } \\
\text { collision)" or the others }\end{array}$ \\
\hline $\begin{array}{l}2 \mathbf{j}_{\mathbf{0}} \mathbf{1} \text { - Wrong way of drive - very } \\
\text { near curb }\end{array}$ & "Crash with obstacle (curb)" \\
\hline 6g2 - Giving priority against rule & $\begin{array}{l}\text { "Crash with moving vehicle (side } \\
\text { collision)" (cause: against } \\
\text { "YIELD TO") or "Crash with } \\
\text { moving vehicle (rear-end } \\
\text { collision)" }\end{array}$ \\
\hline $\begin{array}{l}\mathbf{6 0 2}, \mathbf{6 0 3} \text { etc. - Restriction or } \\
\text { danger in driving during change of } \\
\text { the lane or during exiting the } \\
\text { roundabout (see Figs. } 3 \text { and } 4 \text { ) }\end{array}$ & $\begin{array}{l}\text { "Crash with moving vehicle (side } \\
\text { collision)" (cause: "change of the } \\
\text { lane") }\end{array}$ \\
\hline
\end{tabular}

These traffic accidents (see Tab. 4) are also the most frequent traffic accidents on the monitored roundabouts (see [4] or [5]). We can certify that we can make a prediction of number of traffic accidents (and their kinds) by the video-analysis of conflict situations. On the basis of this video-analysis the transport designer can make necessary adjustments of the roundabouts, which can lead to increase of traffic safety.

Some conflict situations (e.g. 6n2, 6a2 etc.) occur on all types of roundabouts, but on the other hand some situations occur only on some roundabouts. For example situations 602 or 603 (see Fig. 3) occur only on multilane roundabouts. At present this type of roundabouts is usually superseded by turbo roundabouts which certainly cause other conflict situations (due to difficult orientation of the drivers). Conflict situations $4 f_{p} 2,9 j c 2$ or $6 f_{k} 2$ usually occur on urban roundabouts where there are a lot of pedestrians, cyclists and the intersections are close to each other. It's also necessary to realize that some conflict situations (e.g. 6g2) can cause the other secondary situations (e.g. 6D3) which can result in traffic accident (6D4). 
The video-analysis is very good device to analysis of such conflict situations as $2 \mathrm{j}_{\mathrm{o}} 1$. Precise description position and source of this conflict situation can be a great inspiration for traffic designer to design reconstruction of monitored intersection.

In conclusion:

1. The usage of video-recording for analysis of conflict situations is very substantial and advantageous (above all, for possibility of repetition). It is an efficient device on the one hand for analysis of behavior of drivers, pedestrians etc. and on the other hand for monitoring of danger places on the roads, intersections etc.

2. Each modification (although with good intention) can cause the other problems (often more dangerous)!

This article is the result of the project implementation "The influence of structural elements geometry on the safety and fluency of operation in roundabouts and possibility of rise crashes prediction" (CG911-008-910 supported by the Ministry of Transport in the Czech Republic) [4].

\section{References}

[1] FOLPRECHT, J., KRIVDA, V.: Traffic Organization and Control I (in Czech), Ostrava : VSB-TU Ostrava, 2006. ISBN 80-248-1030-1.

[2] KRIVDA, V.: Assessment of Effectiveness of Roundabouts (in Czech), PhD Thesis, Ostrava : VSB-TU Ostrava, 2003. ISBN 80-2480207-4.

[3] KRIVDA, V.: New Findings in the Sphere of the Conflict Situations Analysis on the Czech Republic Road Traffic. Transactions of the VSB-TU Ostrava, Mechanical Series. Ostrava : VSB-TU Ostrava, pp. 161-169, 2009. ISBN 978-80-248-1633-3, ISSN $1210-0471$.

[4] MAHDALOVA, I. et all: Final Report of Project CG911-008-910 "The Influence of Structural Elements Geometry on the Safety and Fluency of Operation in Roundabouts and Possibility of Rise Crashes Prediction" (in Czech), Project of the Ministry of Transport, Czech Republic. Ostrava : VSB-TU, Ostrava, 2011.

[5] MAHDALOVA, I., KRIVDA, V.: Analysis of Traffic Accidents on Roundabouts in the Czech Republic (in Czech), Pardubice : Perner's Contact, No. I, vol. 5. WWW: 〈http://pernerscontacts.upce.cz/>, pp. 156-169, 2010. ISSN 1801-674X. 